MATTERS ARISING

\section{Less specific myositis autoantibodies?}

Brouwer et al studied a very large group of European patients with idiopathic inflammatory myopathies for myositis associated autoantibodies with a variety of methods. ${ }^{1}$ This is the largest group of patients with myositis ever studied for autoantibodies. The results substantially increase the existing knowledge about frequencies of autoantibodies in patients with inflammatory myopathies.

Compared with the pre-existing data, clinical associations of certain myositis-specific autoantibodies seem to be widening and are becoming less specific. Whereas the overwhelming majority of patients with anti-SRP up until now were reported to have polymyositis (PM), ${ }^{23}$ and anti-Mi-2 was almost completely specific for dermatomyositis (DM) ${ }^{3-5}$ Brouwer et al mention several anti-SRP positive DM and anti-Mi-2 positive PM cases, and even some patients with these autoantibodies and inclusion body myositis. The question is whether this is a matter of test or autoantibody specificity or a problem of adequate clinical diagnosis or classification as PM or DM. Moreover, the specificity of myositis related autoantibodies is further questioned by several violations of the well established rule that coincidences of myositis-specific antibodies are almost nonexistent ${ }^{6}$ - for example, by patients being positive for anti-Jo-1 and anti-Mi-2 or anti-SRP at the same time.

As the authors correctly state, the detection of more positive results is mostly due to the assay design, especially of those tests with multiple recombinant fragments of the $\mathrm{Mi}-2$ antigen. The consequence of this gain in sensitivity inevitably is a loss in specificity; whether this can be regarded as progress may be a matter for discussion. The authors do not give information about the diagnostic specificity of the new assays, evaluated by testing healthy controls and patients without myositis, therefore judgment about the relevance of the results is difficult.

The "new", non-DM anti-Mi-2 sera differ from the "classical" ones: Brouwer et al mention that their fine specificity is different and that only $8 / 17$ could be confirmed by western blotting. There is no information as to whether they are positive in the traditional Ouchterlony assay and if they show up as antinuclear antibodies (ANA) in HEp-2 cell immunofluorescence (as the "classical" antiMi-2 sera do). At least the single anti-Mi-2 positive patient with PM previously described by Roux et al was ANA negative.

We wonder if by broadening the anti-Mi-2 specificity its HLA association-previously described as very strong with HLA-DR7 and a tryptophan on residue 9 of DRB1 $1^{5}$ - might also be altered. It would be especially useful to know the HLA type of the four anti-Mi-2 Jo-1 double positive patients described by Brouwer et al because Jo-1 antibodies are highly DR3 associated, ${ }^{38}$ whereas DR3 is completely absent from all Mi-2 positive patients with DM whose HLA type has been published so far. ${ }^{39}$
In conclusion, we fear that by producing more and more positive results in very sensitive assays one does blur the picture of myositis-specific autoantibodies and diminishes their diagnostic value.

R MIERAU T DICK E GENTH

Rheumaklinik Aachen, Burtscheider Markt 24, D 52066 Aachen, Germany

Correspondence to: Dr Mierau

1 Brouwer R, Hengstman GJD, Egberts WV, Ehrfeld H, Bozic B, Ghirardello A, et al. Autoantibody profiles in the sera of European patients with myositis. Ann Rheum Dis 2001;60:11623.

2 Targoff IN, Johnson AE, Miller FW. Antibody to signal recognition particle in po

3 Love LA, Leff RL, Fraser DD, Targoff IN, Dalakas MC, Plotz PH, et al. A new approach to the classifict to the classification of idopathic inflammatory myopathy: myositis-specific autoantibodies de-
fine useful homogeneous patient groups. Medicine (Baltimore) 1991; 70:360-74.

4 Targoff IN, Reichlin $M$. The association between $\mathrm{Mi}$-2 antibodies and dermatomyositis. Arthritis Rheum 1985;28:796-803.

5 Mierau R, Dick T, Bartz-Bazzanella P, Keller E, Albert ED, Genth E. Strong association of dermatomyositis-specific Mi-2 autoantibodies with a tryptophan at position 9 of the HLA-DR $\beta$ chain. Arthritis Rheum 1996;39: 868-76.

6 Targoff IN. Immune manifestations of inflammatory muscle disease. Rheum Dis Clin North Am 1994;20:857-80.

7 Roux S, Seelig HP, Meyer O. Significance of Mi-2 autoantibodies in polymyositis and dermatomyositis. J Rheumatol 1998;25:395-6.

8 Goldstein R, Duvic M, Targoff IN, Reichlin M, McMenemy AM, Reveille JD, et al. HLA-D region genes associated with autoantibody responses to histidyl-transfer RNA synthetase (Jo-1) and other translation-related factors (Jo-1) and other translation-related factors
in myositis. Arthritis Rheum 1990;33: in myosit $1240-8$.

9 Mierau R, Dick T, Genth E, Bartz-Bazzanella P, Keller E, Albert ED. An update on HLA association of Mi-2 autoantibodies: the association with a tryptophan at position 9 of the HLA-DR beta chain is strong but not absolute. Arthritis Rheum 1999;42:1552-3.

\section{Author's reply}

The conclusion of Drs Mierau, Dick, and Genth that by producing more and more positive results in very sensitive assays one blurs the picture of myositis-specific autoantibodies and diminishes their diagnostic value is not correct. The autoantibody specificities we measured remain very specific for myositis and as such still are a useful help for diagnosis. However, our data indeed show that anti-Mi-2 antibodies are not completely specific for dermatomyositis (DM) as has been suggested so far, but also occur in $9 \%$ of patients with polymyositis (PM). ${ }^{1}$ We explained this result by the fact that we used the complete $\mathrm{Mi}-2$ protein (in four overlapping fragments) as antigen, whereas in all previous studies the NM fragment, containing only $26 \%$ of the protein, was coated in the enzyme linked immunosorbent assay (ELISA) assay ${ }^{1}$.

Mierau and colleagues argue that we did not provide information on the diagnostic specificity of the Mi-2 assay we used. The test, in fact, using the four overlapping fragments was evaluated with healthy subjects by testing 84 samples from blood donors. The absorbance values at $405 \mathrm{~nm}$ of the mean plus $3 \mathrm{SD}$ were 0.262 for the NT fragment, 0.260 for the $M$ fragment, and 0.115 for the CT fragment. The cut off values for positivity were set distinctly above those values, that is 0.500 for both the NT and M fragments, and 0.450 for the CT fragment. When this design with rather high cut off values is used, these new tests are specific for the blood donor samples used. To strengthen the argument that anti-Mi-2 antibodies do occur in a significant percentage of patients with PM we successfully confirmed about $50 \%$ of the Mi-2 positives by immunoblotting. Because ELISA is much more sensitive than immunoblotting, or one of the other techniques mentioned by Mierau and colleagues, at this stage of our research we have to accept the fact that $100 \%$ confirmation cannot be reached. Our results thus show that anti-Mi-2 is not as specific for DM as was hitherto thought. The take home message for the clinician is that when anti-Mi-2 autoantibodies are found, the underlying disease might not necessarily be DM.

Mierau and colleagues also correctly state that reported coincidences of myositisspecific antibodies are rare. In our study, containing many patients, such coincidences were found more often, as expected, albeit still in a very low percentage of the patients. Again we think that we found these coincidences by virtue of the very sensitive assays we used for the detection of anti-Mi-2 and anti-SRP antibodies. We disagree, however, that such results inevitably mean a loss in specificity.

Apart from the biochemical refinements mentioned above, there could be a second reason for the discrepancy between previous studies and our results, and that is the problem of adequate diagnosis, as Mierau, Dick, and Genth suggest. In our study we distinguished PM from inclusion body myositis (IBM), which was not the case in previous studies on autoantibody associations. We used established criteria for the diagnosis PM, DM, and IBM..$^{1-3}$ In addition, when anti-Mi-2 autoantibodies were found, patients were, to enable comparison with previous studies, also classified according to the criteria published by Bohan and Peter, ${ }^{4}$ which, however, did not change the diagnosis.

In conclusion, using more sophisticated serological analyses and precise clinical classifications based on established criteria in a large group of patients with myositis, we found that the presence of anti-Mi-2 antibodies is not as exclusive for DM as has been suggested in the past. Instead of blurring the picture of myositis-specific autoantibodies, we may have corrected it.

W J VAN VENROOIJ Department of Biochemistry, University of Nijmegen, Nijmegen, The Netherlands

1 Brouwer R, Hengstman GJD, Vree Egberts W, Ehrfeld H, Bozic B, Ghirardello A, et al. Autoantibody profiles in the sera of European patients with myositis. Ann Rheum Dis 2001;60:116-23.

2 Dalakas MC. Polymyositis, dermatomyositis and inclusion-body myositis. N Engl J Med 1991;325:1487-98.

3 Verschuuren JJ, Badrising UA, van Engelen BGM, van der Hoeven H, Hoogendijk J, Wintzen AR. Inclusion body myositis. In: Emery $\mathrm{AEH}$, ed. Diagnostic criteria for neuromuscular disorders. London: Royal Society of Medicine Press, 1997:81-4.

4 Bohan A, Peter JB. Polymyositis and dermatomyositis (first of two parts). N Engl J Med 1975;292:344-7. 


\section{Usefulness of the HAQ in the clinic}

Greenwood et al have questioned the usefulness of the Stanford Health Assessment Questionnaire (HAQ) in the clinic. ${ }^{1}$ Using Bland and Altman's limits of agreement procedure, ${ }^{2}$ they report that an HAQ score change of at least 0.48 units is required to confidently reflect significant change. We have used the HAQ in the care of our patients for many years and think that their conclusions about the extent of change required and the non-usefulness of the HAQ in clinical care is not correct.

We have replicated the authors' study in paired visits of 443 patients with rheumatoid arthritis (RA) followed up in the clinic by of one of us (FW), and in a survey databank of 2720 patients. Our data are in general agreement with the authors' data.

Using the limits of agreement procedure, we found that the $95 \%$ confidence intervals (CI) for the HAQ were approximately 0.9 for clinic data and 0.6 for survey data. But we also found the following. To exceed $95 \% \mathrm{CI}$, changes in excess of $40 \mathrm{~mm} / 1 \mathrm{st} \mathrm{h}$ for the erythrocyte sedimentation rate (ESR), $70 \mathrm{~mm} \mathrm{Hg}$ for grip strength, 10 joints for a joint count, and four units on 0-10 VAS scales for pain, global severity, and fatigue were required.

Although clinicians may have trouble in interpreting HAQ scores, there is no doubt that one does not need a change of $40 \mathrm{~mm} / 1 \mathrm{st}$ $\mathrm{h}$ for ESR, $70 \mathrm{~mm} \mathrm{Hg}$ for grip, or 10 joints to detect clinical change. These data, which indicate that we cannot reliably do what we are already reliably doing, suggest two interpretations. Firstly, stable measures of overall health are themselves noisy and do not reflect changes in arthritis clinical status. Secondly, they suggest that the Bland-Altman method for agreement and reliability may not work well and may not have a simple interpretation when extrapolated to settings such as these.

In additional analyses that measured relative accuracy and precision, we examined all of the above variables as well as the SF-36 and WOMAC variables using Lin's concordance coefficient. ${ }^{3}$ The HAQ was the most accurate and precise of all of the above variables, with concordance correlations of 0.809 and 0.902 in the two analytic sets.

We also believe it is a mistake to use the HAQ in isolation. One would not treat RA with a sedimentation rate or $\mathrm{C}$ reactive protein (CRP) or joint count alone, and the HAQ should not be used in that manner. In our clinics we collect HAQ, pain, global severity, joint counts, and ESR/CRP, and we use all of these data together to understand the status of the patient. One simple way to do this is to is to assign -1 or 0 or +1 to respective negative, neutral, and positive changes in these variables, and then to add up the individual values. Scores of three or above are associated with significant, clinically important change. Clinicians generally go further and look at the magnitude of the changes to improve further the usefulness of these tests, and for research purposes it is possible to develop a combined standardised score that documents these changes. But clinicians are also Bayesians, and use the HAQ and other clinical measures with knowledge of the particular patient and his longitudinal pattern of responses for each separate variable. We suggest that when the HAQ is used in this manner it provides continuing clinically useful information.
Scientific research in chronic rheumatic diseases will benefit when the clinical investigator brings to the research table the same longitudinal, Bayesian, non-linear insights that the clinician has long had and has long used. The HAQ works in the clinic when used and interpreted appropriately.

F WOLFE

National Data Bank for Rheumatic Diseases, Wichita, KS, USA

T PINCUS Vanderbilt University, Nashville, TN, USA

J F FRIES

Stanford University,

Stanford, CA, USA

Correspondence to: Dr F Wolfe, National Data Bank for Rheumatic Diseases, 1035 N Emporia, Suite 230, Wichita, KS 67214, USA

fwolfe@arthritis-research.org

1 Greenwood MC, Doyle DV, Ensor M. Does the Stanford Health Assessment Questionnaire have potential as a monitoring tool for subjects with rheumatoid arthritis? Ann Rheum Dis 2001;60:344-8.

2 Bland JM, Altman DG. Statistical methods for assessing agreement between two methods of clinical measurement. Lancet 1986;i:310.

3 Lin LI-K. A concordance correlation coefficient to evaluate reproducibility. Biometrics 1989; 45:255-68.

\section{Authors' reply}

We are pleased that Drs Wolfe, Pincus, and Fries have replicated our findings about the level of variability in the Health Assessment Questionnaire (HAQ) for individual patients. We have found the HAQ to be a very useful measure of group outcome. However, in the clinic we work with individual patients and the purpose of our study was to quantify the magnitude of HAQ score change which would be needed reliably to reflect significant change from a patient's perspective. The calculated confidence intervals formally quantify the observation that an HAQ score can change by a considerable amount over just a short period of time, in the absence of any change in health perceived by the patient. The method evaluates expected levels of agreement under defined circumstances (in our case no change in health perceived by the patient over two months). Different levels of confidence can be chosen according to requirements. However, the sensible application of the method depends on giving serious consideration to the nature of the concept being measured and how the results are paired.

We too have found a similar range of variability for individual patients, in a whole range of standard outcome variables, which we would suggest is a function of their subjectivity and consequent susceptibility to other factors, such as mood. However, conventional outcome measurement remains a useful tool for recording group progress over time.

We quite agree that in clinical practice it would be unreasonable to attempt to use any measure in isolation. However, in order to integrate multiple pieces of evidence in a Bayesian manner it is necessary to have some idea of the probabilities involved. We set out to provide such information for the HAQ with a view to assisting clinicians in their interpretation of HAQ score changes in the light of all other available evidence. However, in the event, the amount of subjective variability was such that we feel it cannot reliably be used to influence or fully explain management changes for individual patients.

In an era when clinicians are having to argue for access to new and expensive treatments such as infliximab and etanercept we need an outcome measure which will reliably reflect individual responses over relatively short time intervals (perhaps 6-12 months), and practising clinicians need to understand the limitations of the measurement tools they use.

M GREENWOOD
D DOYLE
Whipps Cross University Hospital,
Rheumatology Department,
Whipps Cross Road,
Leytonstone,
London E11 1NR, UK

\section{LETTERS TO THE EDITOR}

\section{Multinodular goitre with giant cell vasculitis of thyroid arteries in a woman with temporal arteritis}

Previous studies have suggested that patients with giant cell arteritis (GCA) or polymyalgia rheumatica (PMR) may be at increased risk for thyroid dysfunctions. ${ }^{1}$ To our knowledge, histologically confirmed thyroid arteritis in a case of GCA has never been described.

A 67 year old woman, complained in September 1994 of left sided headaches, jaw claudication, and transient visual disturbance of her left eye. Biological evaluation showed an inflammatory process, and biopsy of the left temporal artery was typical of GCA. Steroids were started $(1 \mathrm{mg} / \mathrm{kg} /$ day prednisolone) with initial clinical and biological improvement, but a steroid dependency was noted when the dose was reduced to under 40 $\mathrm{mg}$ /day. On successive clinical evaluations, we noticed an increase in the volume of the thyroid gland. Ultrasonography showed a multinodular goitre with heterogeneous nodules characterised by either cystic or solid appearance. Thyroid function tests were normal and a search for antithyroid antibodies (antimicrosomal and antithyroglobulin antibodies) was negative.

Owing to the increase in volume of the goitre and the increased number of nodules (the largest nodule measured $2.5 \mathrm{~cm}$ ), a total thyroidectomy was performed in February 1997 (29 months after the onset of temporal arteritis). Histopathological analysis concluded that there was a multinodular goitre with benign adenomas. Analysis of the left superior thyroid artery showed an inflammatory granulomatous lesion with giant cells in the elastica externa (fig 1), whereas the right superior thyroid artery was normal. At that time, the patient was treated with prednisolone $(20 \mathrm{mg} /$ day) and there was a mild biological inflammatory process (erythrocyte 


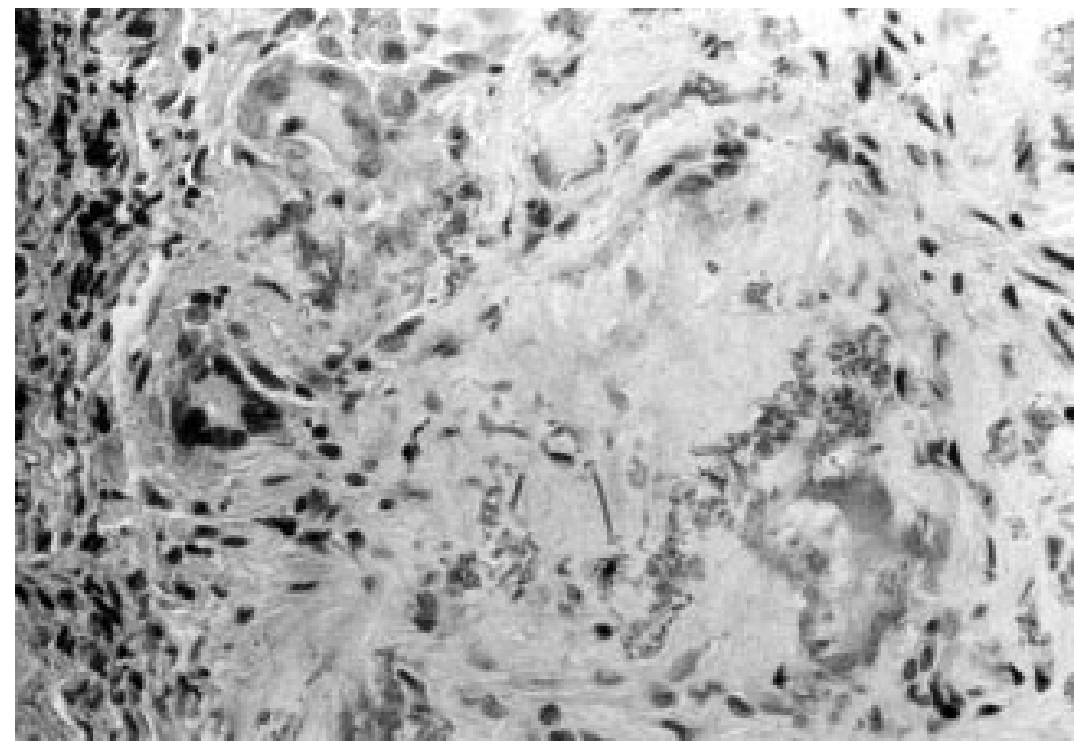

Figure 1 Histopathological analysis of thyroid gland (haematoxylin-eosin-saffron, original magnification $\times 250$ ). Giant cells and granulomatous inflammatory infiltrate near fragmented elastica tunica.

sedimentation rate $21 \mathrm{~mm} / 1 \mathrm{st} \mathrm{h}$ and $\mathrm{C}$ reactive protein $10 \mathrm{mg} / \mathrm{l})$. A search for antinuclear, anti-extract cell antigen, and anticardiolipin antibodies as well as lupus anticoagulant was negative. Treatment with methotrexate was added $(10 \mathrm{mg} /$ week $)$, which allowed progressive tapering of the prednisolone dose.

At her last medical visit in April 2000 the clinical and biological outcome was good without any sign of relapse in the GCA. Treatment with prednisone (2 $\mathrm{mg} /$ day), methotrexate $(10 \mathrm{mg} /$ week), and L-thyroxine (125 $\mu \mathrm{g} /$ day) was continued.

Associations of thyroid dysfunctions and GCA have included hypothyroidism, ${ }^{23}$ thyrotoxicosis, ${ }^{4}$ Graves's disease, ${ }^{5}$ and de Quervain's thyroiditis. ${ }^{6}$ In the series of Bowness et al $10 \%$ of the 367 patients with PMR or GCA, or both, had antithyroid autoantibodies and $4.9 \%$ had clinical and biochemical hypothyroidism requiring replacement treatment with thyroxine, which was significantly greater than in the control group. ${ }^{3}$ To explain the association between PMR and/or GCA and autoimmune thyroid diseases, the authors suggested a common aetiological agent (perhaps infective) or a common immunological predisposition. However, a recent multicentre case-control study on 285 patients with GCA failed to show a significant relation with thyroid diseases.

The involvement of non-classical organs in GCA with histologically proved vasculitis has been reported for coronary, renal, hepatic, and female genital tract arteries. ${ }^{8}$ As thyroid arteries are branches of the external carotid artery, the occurrence in our observation of GCA and nodular goitre with thyroid arteritis was probably not fortuitous. Moreover, GCA was seen on the same side of the head and neck (respectively left temporal artery and left superior thyroid artery). To our knowledge, only one previous observation of an inflammatory infiltrate of the thyroid gland, comprising multinucleated giant cells, has been reported and concerned subacute thyroiditis occurring simultaneously with GCA. ${ }^{9}$ As the sample was obtained by thyroid aspiration, the author could not conclude that there was GCA involvement. ${ }^{9}$
From a pathophysiological point of view we feel that, in our case, thyroid ischaemic lesions (often seen in goitres ${ }^{10}$ ) and/or inflammatory infiltrate induced by the vasculitis process may have played a part in the formation of the goitre. Thus a possible link between GCA and goitre must be kept in mind.

B GRANEL J SERRATRICE B CHAUDIER J REY

LWIADER $\mathrm{X}$ PACHE

C CHRISTIDES

P DISDIER

P J WEILLER

Service de Médecine Interne, Hôpital de la Timone, 264 Rue Saint Pierre,

Marseille, France

C DE MICCO Service d'Anatomie Pathologique, Hopital Nord, Chemin des Bourelly, 13915 Marseille, France

J F HENRY

Service de Chirurgie Endocrinienne, Hôpital de la Timone

Correspondence to: Dr P Disdier, Service de Médecine Interne, Hôpital de la Timone, 264 Rue Saint-Pierre, 13385 Marseille Cedex 5, France pdisdier@ap-hm.fr

1 Nicholson GC, Carroll WM, Gutteridge DH, Armstrong BK. Autoimmune thyroid disease and giant cell arteritis: a review, case report and epidemiological study. Aust NZ J Med 1984;14:487-90

2 Wiseman P, Stewart K, Rai GS. Hypothyroidism in polymyalgia rheumatica and giant cell arteritis. BMJ 1989;ii:647-8.

3 Bowness P, Shotliff K, Middlemiss A, Myles AB. Prevalence of hypothyroidism in patients with polymyalgia rheumatica and giant cell arteritis. Br J Rheumatol 1991;30:349-51.

4 Thomas RD, Croft DN. Thyrotoxicosis and giant cell arteritis. BMJ 1974; ii:408-9.

5 Disdier P, Swiader L, Bolla G, Figarella-Branger $\mathrm{D}$, Denizot A, Harlé JR, et al. Association maladie de Horton-hyperthyroïdie. Presse Med die de Hortor
1994;23:37.

6 Milioniz HJ, Elisaf MS, Drosos AA, Tsatsoulis AA. Concurrence of giant cell arteritis in a patient with de Quervain's thyr
Endocrinol (Oxf) 1997;47:760-1.
7 Duhaut $\mathrm{P}$, Bornet $\mathrm{H}$, Pinède L, DemolombeRagué S, Loire R, Seydoux D, et al. Giant cell arteritis and thyroid dysfunction: multicentre case-control study. BMJ 1999;318:434-5.

8 Sonnenblick M, Nesher G, Rosin A. Nonclassical organ involvement in temporal arteritis. Semin Arthritis Rheum 1989;19:183-90.

9 Arend SM, Westedt MI. Simultaneous onset of giant cell arteritis and subacute thyroiditis. Ann Rheum Dis 1993;52:839.

10 Cabanne F, Bonenfant JL, eds. Anatomie pathologique. Paris: Maloine, 1980.

\section{Giant cell arteritis associated with demyelinating polyradiculoneuropathy}

Peripheral nerve involvement-mononeuritis, ${ }^{1}$ mononeuritis multiplex, and polyneuropathies ${ }^{2}$ - has been reported in $14 \%$ of patients with giant cell arteritis (GCA). ${ }^{34}$ GCA associated with acute inflammatory demyelinating polyneuropathy (AIDP) has exceptionally been described. ${ }^{56}$ We report an unusual case of this association.

A 67 year old woman presented with a one month history of difficulty in walking, weakness, and proximal myalgia that worsened progressively. Examination showed proximal weakness and abolition of all deep tendon reflexes; there was no sensory deficit and cranial nerve function was normal. Laboratory tests disclosed normal haematological findings with an erythrocyte sedimentation rate (ESR) of $12 \mathrm{~mm} / 1 \mathrm{st} \mathrm{h}$; renal and liver function tests, muscle enzymes, and thyroid stimulating hormone were in the normal range. Serum protein electrophoresis, antinuclear antibodies and rheumatoid factors, and serology for Lyme disease, $\mathrm{Q}$ fever, mycoplasma, Venereal Disease Research Laboratory test, HIV, and cytomegalovirus were all negative. Chest radiographs and abdominal echography were normal. Electrophysiological investigation disclosed an inflammatory demyelinating polyradiculoneuropathy, with prominence of motor and proximal involvement. The cerebrospinal fluid (CSF) showed four mononuclear cells $/ \mathrm{ml}$; protein $0.56 \mathrm{~g} / 1$ and glucose $3.4 \mathrm{mmol} / 1$.

At this moment, an AIDP or GuillainBarré syndrome was diagnosed, and plasma exchange was performed, using standard procedures. After the second plasma exchange, the weakness had completely disappeared, but the patient started with fever $\left(40^{\circ} \mathrm{C}\right)$ and increasing bitemporal and occipital headache. Physical examination showed that temporal and occipital arteries were nodular and swollen with palpable pulse. Laboratory tests disclosed haemoglobin $78 \mathrm{~g} / 1$, platelet count $999 \times 10^{9} / 1$, ESR $94 \mathrm{~mm} / 1 \mathrm{st} \mathrm{h}$, alkaline phosphatase $170 \mathrm{U} / 1$, and $\gamma$-glutamyltransferase $99 \mathrm{U} / 1$. Temporal artery biopsy disclosed changes typical of GCA. Treatment with prednisone orally 1 $\mathrm{mg} / \mathrm{kg}$ weight was started. There was an excellent response, the symptoms stopped within days and the ESR and liver function test returned to normal. Prednisone was reduced gradually over time. Repeated nerve conduction studies showed an objective improvement.

Ten months later, when she was taking prednisone $10 \mathrm{mg} /$ day, the proximal weakness started again, worsening over the following weeks. Electrophysiological study showed 


\begin{tabular}{|c|c|c|c|}
\hline & Case $1^{5}$ & Case $2^{6}$ & This study \\
\hline Age/sex & $71 /$ female & 73/male & 67/female \\
\hline Headache & Yes & Yes & Yes \\
\hline Fever & No & No & Yes \\
\hline Visual loss & Yes & No & No \\
\hline Facial diplegia & Yes & Yes & No \\
\hline $\mathrm{PMR}^{\star}$ symptoms & No & No & No \\
\hline Latency between $\mathrm{GCA}^{\star}$ and $\mathrm{PN}^{\star}$ & AIDP $^{\star}$ occurred 2 weeks before GCA & $\begin{array}{l}\text { GCA preceded AIDP by } 4 \text { months } \\
\text { AIDP }\end{array}$ & $\begin{array}{l}\text { First episode of AIDP occurred } 2 \text { weeks } \\
\text { before GCA }\end{array}$ \\
\hline \multicolumn{4}{|l|}{ Laboratory tests } \\
\hline $\mathrm{ESR}^{\star}(\mathrm{mm} / 1 \mathrm{st} \mathrm{h})$ & 125 & 125 & 94 \\
\hline $\mathrm{CSF}^{\star}$ & Protein $0.1 \mathrm{~g} / 1$; acellular & Protein $3 \mathrm{~g} / \mathrm{l}$; acellular & Protein $0.56 \mathrm{~g} / 1$; cells $4 / \mathrm{ml}$ \\
\hline Temporal artery biopsy & Not done & GCA & GCA \\
\hline Nerve conduction study & Normal & AIDP & AIDP \\
\hline Treatment & Prednisolone, $80 \mathrm{mg} /$ day & Prednisone $75 \mathrm{mg} /$ day, $\mathrm{PEX}^{\star}$ & Prednisone 60 mg/day, PEX, IVIg* \\
\hline \multirow[t]{2}{*}{ Clinical outcome } & \multirow{2}{*}{$\begin{array}{l}\text { Spontaneous improvement of the AIDP, } \\
\text { symptoms of GCA were controlled with } \\
\text { steroids }\end{array}$} & $\begin{array}{l}\mathrm{TIA}^{\star} \text { during GCA prednisone } \\
\text { treatment }\end{array}$ & \multirow{2}{*}{$\begin{array}{l}\text { Cure of GCA with prednisone; } \\
\text { improvement of the AIDP with PEX } \\
\text { and relapse } 8 \text { months later, clinically } \\
\text { controlled with prednisone and IVIg }\end{array}$} \\
\hline & & Cure of the AIDP with PEX & \\
\hline
\end{tabular}

$\overline{\star P M R}=$ polymyalgia rheumatica $; \mathrm{GCA}=$ giant cell arteritis; $\mathrm{PN}=$ polyneuropathy $; \mathrm{ESR}=$ erythrocyte sedimentation rate; $\mathrm{CSF}=$ cerebrospinal fluid; AIDP = acute inflammatory demyelinating polyradiculoneuropathy; PEX = plasma exchange; TIA = transient ischaemic attack; IVIg = intravenous immunoglobulin.

progression of the demyelinating polyradiculoneuropathy. She had no other symptoms. Haematological and blood chemical findings were all normal, as was the ESR. Plasma exchange sessions were restarted. The diagnosis at this time was an AIDP relapsing form. Prednisone was given at $1 \mathrm{mg} / \mathrm{kg}$ weight. She improved rapidly. Because of the serious side effects she had previously had with the steroid treatment $(30 \mathrm{~kg}$ weight gain, hyperglycaemia, mental changes) and the poor vascular access she had for the plasma exchange, we decided to start treatment with intravenous immunoglobulin pulses, $0.4 \mathrm{~g} / \mathrm{kg}$ weight every four weeks. Steroids were tapered and the patient remained clinically well during the following year.

To our knowledge, only two cases of GCA associated with AIDP have been previously reported (table 1), and no association of GCA with the AIDP relapsing form has been previously described. The first case refers to a patient who presented a clinical picture of AIDP and in whom temporal arteritis was diagnosed two weeks later. ${ }^{5}$ In the second case the patient was diagnosed as temporal arteritis, ${ }^{6}$ with a compatible biopsy; he was treated with prednisone and four weeks later he presented a generalised weakness: CSF and electrophysiological study were concordant with AIDP. A sural nerve biopsy was not done in these cases.

The neuropathies associated with temporal arteritis and other vasculitis have been attributed to ischaemic lesions of the nerves due to an arteritis of the vasa nervorum. A vasculitic neuropathy was excluded in our case because the clinical course and the electrophysiological study were characteristic of AIDP.

The underlying cause and pathogenic mechanisms of AIDP and GCA are not well understood. Immune cellular mechanisms have an important role: an increasing number of $\mathrm{T} \mathrm{CD} 4+$ cells and macrophages in demyelinated regions of the nerve are seen in $\mathrm{AIDP}^{7}$; the histopathology of GCA shows a mixed inflammatory infiltrate with $\mathrm{T}$ CD4+ lymphocytes and macrophages secreting proinflammatory cytokines. ${ }^{8}$

Temporal arteritis associated with inflammatory demyelinating polyradiculoneuropathy may be a coincidence, but a common inmunological pathogenesis, probably based on a cellular $\mathrm{T}$ cell dependent mechanism and related to a cytokine deregulation, cannot be ruled out. Infectious agents, such as a virus, may be the cause of the onset of both diseases in a subset of patients. ${ }^{79}$

\section{$M$ GARCÍA GASALLA $M$ YEBRA BANGO J A VARGAS NÚÑEZ S MELLOR PITA \\ M GARCÍA ALVARADO A DE ABAJO ALONSO Department of Internal Medicine, Clínica Puerta de Hierro, Madrid, Spain \\ G GOIZUETA \\ Department of Neurophysiology}

Correspondence to: Dr M Yebra Bango, Servicio de Medicina Interna I, Clínica Puerta de Hierro, C/ San Martín de Porres No 4, 28035 Madrid, Spain

1 Vargas JA, Yebra M, Jiménez C, Menéndez JL. Arteritis temporal y neuropatía periférica. Med Arteritis temporal y neurop
Clin (Barc) 1986;87:565-6.

2 Reich KA, Gianrsiracusa D, Strongwater SL. Neurologic manifestations of giant cell arteriNeurologic manifestations of gian
tis. Am J Med 1990;89:67-72.

3 Caselli RJ, Hunder GG. Neurologic aspects of giant cell arteritis. Rheum Dis Clin North Am 1993; 19:941-53.

4 Caselli RJ, Daube JR, Hunder GG, Whisnant JP. Peripheral neuropathic syndromes in giant cell (temporal) arteritis. Neurology 1988;38: 685-9.

5 Corston RN. Temporal arteritis in association with the Guillain-Barré syndrome. BMJ 1980; 280:292-3.

6 Tiab M, Raffi F, Hamidou M, Mussini JM, Barrier JH. Syndrome de Guillain Barré au cours d'une maladie de Horton. Rev Med Interne 1994;15:772-3.

7 Arnason BG, Soliven B. Acute inflammatory demyelinating polyradiculoneuropathy. In: demyelinating polyradiculoneuropathy. In: Dyck PJ, Thomas PK, eds. Peripheral neuropa-
thy. 3rd ed. Philadelphia: Saunders, 1993: thy. 3rd $1437-85$.

8 Amouroux J. Anatomie pathologique des artérites à cellules géantes. Ann Med Interne 1998;149:415-19.

9 Duhaut P, Bosshard S, Calvet A, Pinede L, Demolmbe-Rague S, Dumontet C, et al. Giant cell arteritis, polymyalgia rheumatica, and viral hypotheses: a multicenter, prospective casecontrol study. J Rheumatol 1999;26:361-9.

\section{Oral steroid in the treatment of carpal tunnel syndrome}

A range of options are available for the conservative treatment of carpal tunnel syndrome (CTS). ${ }^{1-4}$ Non-operative methods include immobilisation of the affected hand with wrist splint; local injection of steroids and drugs such as diuretics and non-steroidal anti-inflammatory drugs. ${ }^{6-11}$ These oral drugs are thought to decrease the volume of swollen tissue within the CTS and are widely used, but there is limited clinical evidence for their role.

This prospective randomised, double blind, placebo controlled study aimed at evaluating the effect of oral steroids in the symptomatic treatment of CTS. We recruited patients with newly diagnosed CTS of more than three months' duration with confirmatory electrophysiological results (prolonged median nerve distal motor latencies $>4 \mathrm{~ms}$ or median ulnar palmar sensory latency difference $>0.5 \mathrm{~ms}$ ) including electromyographic recordings of the abductor pollicis brevis $(\mathrm{APB})^{5}$; co-interventions such as drug or injection treatment were withheld during the study. Exclusion criteria included ( $a$ ) patients with evidence of severe CTS: fibrillation potentials or reinnervation on needle examination of the APB; $(b)$ coexisting disorders or conditions which may mimic CTS, such as cervical radiculopathy or peripheral neuropathy; (c) contraindication to steroid use; and (d) history of underlying disorders associated with CTS, such as diabetes mellites or rheumatoid arthritis.

Patients who fulfilled the criteria were treated conservatively for two months with splinting. If symptomatic after this period, patients were allocated, using a random computer generated code, to a 10 day course of prednisolone $25 \mathrm{mg} /$ day or a 10 day course of placebo. Both were given as single tablets which were identical in appearance. A physician (SMW) unaware of the treatment allocation assessed the mean global symptom score (GSS) of all patients at two and eight weeks. This is a scoring system first devised by Herskovitz which rates symptoms on a scale of 0 (no symptoms) to 10 (severe) in five categories: pain, numbness, paraesthesia, weakness/clumsiness, and nocturnal awakening. The sum of the scores in each category was the GSS. ${ }^{10}$ Median (interquartile range (IR)) changes in GSS at two and eight weeks from baseline were analysed using the Mann-Whitney test. The null hypothesis was that there was no difference in symptom score between the treatment and placebo groups. Results were considered significant at $\mathrm{p}<0.05$ (two sided). The sample population of 36 was planned to enable achievement of $80 \%$ power with an $\alpha=0.05$ for detecting a $50 \%$ difference in GSS between the treatment groups, assuming 
Table 1 Patient characteristics

\begin{tabular}{|c|c|c|}
\hline & Placebo & Steroids \\
\hline Patient numbers & 18 & 18 \\
\hline Age, years (mean (SD)) & $44.9(10.0)$ & 42.9 \\
\hline Sex (female/male) & $17 / 1$ & $17 / 1$ \\
\hline Baseline GSS ${ }^{\star}$, (median, IR ${ }^{\star}$ ) & $24 \quad(16-26)$ & $20 \quad(18-26)$ \\
\hline CMAP amplitude, $\mathrm{mV}$ (mean (SD)) & $12.95(3.40)$ & $14.49(3.01)$ \\
\hline Distal motor latencies, ms (mean (SD)) & $5.08(1.20)$ & $4.97(0.84)$ \\
\hline \multicolumn{3}{|l|}{ Location of CTS ${ }^{\star}$} \\
\hline Right & 10 & 9 \\
\hline Left & 2 & 3 \\
\hline Bilateral & 6 & 6 \\
\hline
\end{tabular}

${ }^{\star}$ GSS = global synptom score; IR = interquartile range; $\mathrm{CTS}=$ carpal tunnel syndrome.

the response rate in the oral steroid group to be $80 \%$ and that of the placebo group $30 \%$

Thirty six patients were recruited, of whom half were randomly allocated to receive oral steroids and half to placebo. There was no significant difference in demographics such as age and in the severity of electrophysiological parameters as shown in table 1. As compared with baseline, patients receiving steroid had a median (IR) change of -12.5 $(-15$ to -7$)$ at two weeks, whereas the placebo group was -4.5 ( -14 to 0$), p=0.027$ as shown in fig 1A. After eight weeks, the median (IR) reduction of GSS in the steroid group was $-9(-14$ to -6$)$ and in the placebo group -2 ( -10 to 0$), p=0.034$ as shown in fig 1B. The median differences between the two groups at two and eight weeks were $-6(-11$ to -1$)$ and -6 ( -11 to 0$)$ respectively. All patients completed the short course of treatment.

This study shows a small but statistically significant reduction in GSS in the group prescribed a short course of prednisolone as compared with placebo. Steroid may have a role in the treatment of mild to moderate
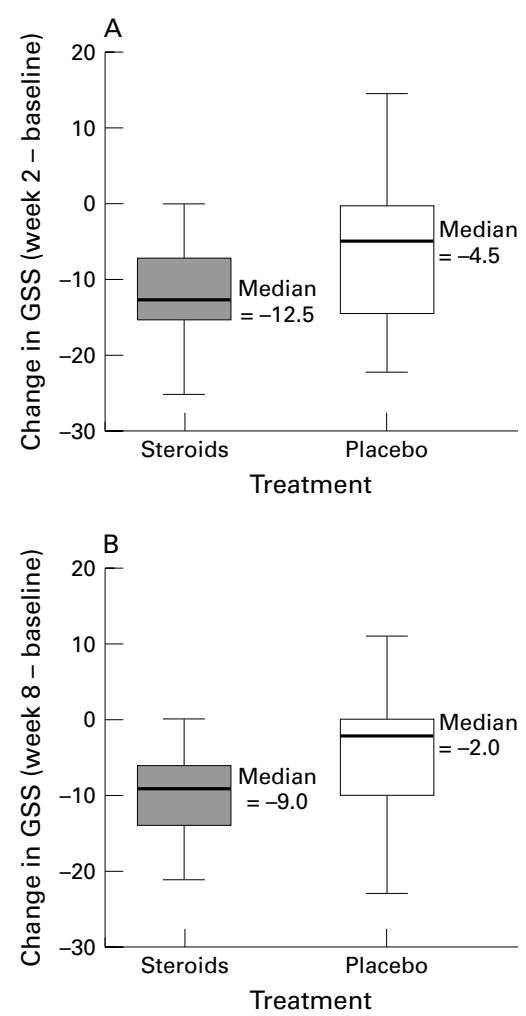

Figure 1 Box plots of changes in global symptom score (GSS) at (A) two weeks and (B) eight weeks.
CTS in patients who decline or who are awaiting surgical decompression. Further trials with larger sample size and longer follow up, using low dose oral steroid in direct comparison with injected steroid, would further clarify the effect of this treatment.

A C F HUI $S M$ WONG K S WONG

$\mathrm{R}$ KAY Department of Medicine

P YUNG

L K HUNG

Department of Orthopaedics, Prince of Wales Hospital,

The Chinese University of Hong Kong

L M YU

Centre for Clinical Trials and Epidemiological Research,

The Chinese University of Hong Kong

Correspondence to: Dr S M Wong, Department of Medicine, Prince of Wales Hospital, 30-32 Ngan Shing Street, Shatin, New Territories, Hong Kong, Special Administrative Region China

1 Preston DC. Distal median neuropathies. Neurol Clin 1999;17:407-24.

2 Spinner RJ, Bachman JW, Amadio PC. The many faces of carpal tunnel syndrome. Mayo Clin Proc 1989;64:829-36.

3 Rosenbaum RB, Ochoa JC. Carpal tunnel syndrome and other disorders of the median
nerve. Boston: Butterworth-Heinemann, 1993: nerve. B

4 Duncan KH, Lewis RC Jr, Foreman KA, Nordyke MD. Treatment of carpal tunnel syndrome by members of the American Society for Surgery for the Hand: results of a questionnaire. J Hand Surg [Am] 1987; 12:384-91.

5 American Academy of Neurology, American Association of Electrodiagnostic Medicine, American Academy of Physical Medicine and Rehabilitation. Practice parameter for electrodiagnostic studies in carpal tunnel syndrome (summary statement). Neurology 1993;43: 2404-5.

6 Kruger VL, Kraft GH, Deitz JC, Ameis A, Polissar L. Carpal tunnel syndrome: objective Polissar L. Carpal tunnel syndrome: objective measures and splint use.
bil 1991;72:517-20.

7 Green DP. Diagnostic and therapeutic value of carpal tunnel injection. J Hand Surg [Am] 1984;9:850-4

8 Ozdogan H, Yazici H. The efficacy of local steroid injections in idiopathic carpal tunnel syndrome: a double blind study. Br J Rheum tol 1984;23:272-5.

9 Girlanda P, Dattola R, Venuto C, Mangiapane R, Nicolosi C, Messina C. Local steroid $\mathrm{R}$, Nicolosi C, Messina C. Local steroid
treatment in idiopathic carpal tunnel treatment in idiopathic carpal tunnel
syndrome: short and long term efficacy. J Neurol 1993;240:187-90.

10 Herskovitz S, Bergre AR, Lipton RB. Low dose, short term oral prednisone in the treatment of carpal tunnel syndrome. Neurology 1995;45: 1923-5.

11 Chang MH, Chiang HT, Lee SS, Ger LP, Lo YK. Oral drug of choice in carpal tunnel syndrome. Neurology 1998:51:390-3.

\section{Parvovirus B19 infection in Behçet's disease}

We read with great interest the article by Kerr which reviewed present knowledge about the possible association of parvovirus B19 infection with various connective tissue and autoimmune disorders. ${ }^{1}$ The author concluded that data implicating B19 virus infection in the aetiopathogenesis of rheumatic diseases are insufficient and conflicting. Although a significant number of studies support a possible role for the virus in the pathogenesis of rheumatoid arthritis, juvenile idiopathic arthritis, systemic lupus erythematosus, and vasculitis, the author believes that B19 infection is only one of a number of triggers.

Behçet's disease (BD) is a multisystem disorder originally described by the Turkish dermatologist Hulusi Behçet. ${ }^{2}$ Although its cause is unknown, vasculitis is widely accepted as the underlying pathological process. ${ }^{3}$ As stated by the author, various case reports have been published demonstrating the presence of B19 virus in patients with vasculitic syndromes. ${ }^{45}$ Viral infections have also been postulated as triggering factors in BD. Therefore, in a previous study that was not cited in the report by Kerr, we investigated a possible role of B19 virus in BD. ${ }^{6}$ We assessed antibodies against parvovirus B19 in serum samples from 41 patients with $\mathrm{BD}$ and from 40 age and sex matched controls. Six patients with BD (15\%) had anti-B19 IgM antibodies while no IgM antibodies were detected in the control group $(\mathrm{p}=0.03)$. However, anti-B19 IgG antibodies were present in 23 patients with BD and 25 controls. There was also no correlation between the presence of anti-B19 IgM antibodies and articular and vascular manifestations of $\mathrm{BD}(\mathrm{p}=0.9$ and $\mathrm{p}=0.5$, respectively). Therefore, we concluded that our findings did not strongly support the involvement of B19 in the pathogenesis of $\mathrm{BD}$, and we also concluded that serological evidence of acute B19 infection in six patients with BD might have been coincidental. However, the presence of anti-B19 IgM antibodies in patients with $\mathrm{BD}$ might provide evidence for the place of B19 infection in the pathobiology of BD. As far as we know our previous report is the only published study investigating the association of $\mathrm{B} 19$ virus infection and $\mathrm{BD}$. Therefore, further studies will be clearly needed to clarify this unresolved issue.

$$
\begin{array}{r}
\text { S KIRAZ } \\
\text { M A ÖZTÜRK } \\
\text { I ERTENLI } \\
\text { M CCALGÜNERI } \\
\text { Hacettepe University School of Medicine, } \\
\text { Department of Rheumatology, } \\
\text { Ankara, Turkey }
\end{array}
$$

Correspondence to: $\operatorname{Dr}$ M A Öztürk, Ostim mahallesi 89. sokak AK-84 sitesi A-2 blok no: 8, TR-06170, Yenimahalle, Ankara-Turkey makifozturk@yahoo.com

1 Kerr JR. Pathogenesis of human parvovirus B19 in rheumatic diseases. Ann Rheum Dis 2000; 59:672-83.

2 Behçet $\mathrm{H}$. Über rezidivierende aphthose, durch ein Virus verursachte Geschwure am Mund, am Auge und an der Genitalien. Dermatol Wochenschr 1937;105:1152-7.

3 O'Duffy JD. Vasculitis in Behçet's disease. Rheum Dis Clin North Am 1990;16:423-31.

4 Sezer N. Further investigations on the virus of Behçet's disease. Am J Ophthalmol 1956;41: 41-55.

5 Eglin RP, Lehner T, Subak-Sharpe JH. Detection of RNA complementary herpes simplex virus in mononuclear cells from patients with Behçet's mononuclear cells from patients with Behçet's 1982;ii: $1356-60$. 
6 Kiraz S, Ertenli I, Benekli M, Çalgüneri M. Parvovirus B19 infection in Behçet's disease. Clin Exp Rheumatol 1996;14:71-3.

\section{Idiopathic dilatation of the pulmonary artery in a patient with dermatomyositis complicated by interstitial pneumonitis}

Idiopathic dilatation of the pulmonary artery (IDPA) is an uncommon anomaly occurring in $0.6 \%$ of patients with congenital heart disease, ${ }^{12}$ and may be bilateral or unilateral. ${ }^{3-9}$ We report on a patient with IDPA who concomitantly developed polymyositis (PM) and interstitial pneumonitis (IP).

On 25 August 1997 a 63 year old woman was referred to our hospital because of dyspnoea, pyrexia, arthralgia, raised levels of aspartate aminotransferase (AST) and lactate dehydrogenase $(\mathrm{LDH})$, and bilateral diffuse shadows on chest $x$ ray examination.

On admission, a fine crackling sound was audible in the lung fields. We could not confirm Gottron's sign and heliotrope erythema. Laboratory examination disclosed increases of $\mathrm{LDH}$ (1194 IU/1), AST (61 IU/1), creatinine kinase (CK; 2078 IU/1), and aldolase (36.8 IU/1) in the serum samples. Autoantibodies were negative except for antinuclear antibody (1/40). Lymphopenia $(600 / \mu \mathrm{l})$ and accelerated erythrocyte sedimentation rate (ESR; $75 \mathrm{~mm} / 1 \mathrm{st} \mathrm{h}$ ) were seen. The radiological examination showed diffuse granular shadows and dilatation of the pulmonary arteries (PAs) (Fig 1A). Findings of electrocardiography, echo cardiography, and blood gas analysis (BGA) were unremarkable. Pulmonary function was compatible with IP: percentage predicted value for vital capacity was 71.7 , for forced
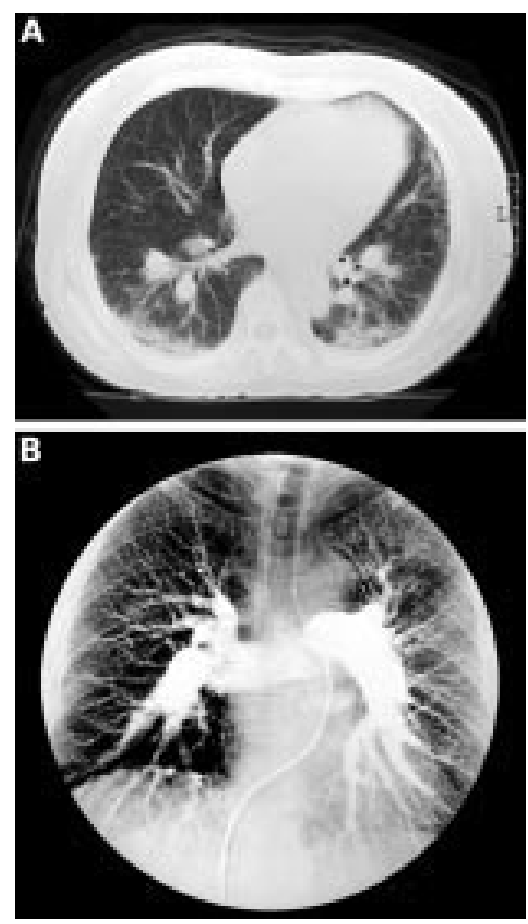

Figure1 Computed tomography findings and pulmonary arteriography. expiratory volume per second 110.0, and for carbon monoxide transfer factor was 61.8 .

We performed transbronchial lung biopsy, a right heart catheterisation study, and electromyography. The lung biopsy samples were compatible with IP (fibrosis with Masson body). The catheterisation study disclosed dilatation of the PAs without pulmonary hypertension $(\mathrm{PH}$; mean pulmonary pressure was $20 \mathrm{~mm} \mathrm{Hg}$; fig 1B). An electromyograph of the right biceps muscle manifested low amplitude and short duration. We thus diagnosed her as having IDPA complicated with PM related IP.

During such examinations, pyrexia failed to subside, and BGA on 31 August deteriorated $\left(\mathrm{PaO}_{2} 67.4 \mathrm{~mm} \mathrm{Hg}\right.$ and $\mathrm{PaCO}_{2} 40.3 \mathrm{~mm}$ $\mathrm{Hg})$. Prednisolone $(40 \mathrm{mg} /$ day $)$ was started from 17 September. The fever subsided, and the laboratory data improved on the day of discharge (31 October): LDH decreased from 1082 to $738 \mathrm{IU} / 1$, CK from 1885 to 223 IU/1, AST from 60 to $18 \mathrm{IU} / 1$, ESR from 116 to $27 \mathrm{~mm} / 1 \mathrm{st} \mathrm{h}$, and white blood cell count from 19000 to $9600 / \mu l$. Data of pulmonary function tests including BGA were unchanged. While taking $30 \mathrm{mg}$ prednisolone a day, she visited crowded stores and thereafter developed pyrexia with severe dyspnoea. BGA showed hypoxaemia $\left(\mathrm{PaO}_{2} 45.2 \mathrm{~mm} \mathrm{Hg}\right.$ and $\mathrm{PaCO}_{2} 35.3 \mathrm{~mm} \mathrm{Hg}$ ). Laboratory data on readmission showed LDH $1581 \mathrm{IU} / 1, \mathrm{CK}$ $169 \mathrm{IU} / 1$, AST $25 \mathrm{IU} / 1$, ESR $122 \mathrm{~mm} / 1 \mathrm{st} \mathrm{h}$, C reactive protein $212 \mathrm{mg} / \mathrm{l}$, white blood cell count $15100 / \mu \mathrm{l}$, and platelets $60000 / \mu 1$. We diagnosed her as having exacerbated IP induced by infection and started treatment with pulse methylprednisolone (1000 mg/day for three days) followed by antibiotics, antimycotics, pentamidine, and immunoglobulin (high titres for cytomegalovirus).

Despite such treatments, she died of respiratory failure on 10 November. Necropsy disclosed (a) polymyositis showing focal atrophy, fibrosis, and contraction band necrosis; (b) IP with cytomegalic inclusion body; (c) dilatation of the bilateral PAs; and (d) disseminated intravascular coagulation.

Because dilatation of the PA can be caused by rheumatic diseases through secondary $\mathrm{PH}$, diagnosis of IDPA is difficult among such patients. Our patient had PM associated IP; we thus initially supposed that she had both IP and PH complicated with PM. Pulmonary catheterisation showed the absence of $\mathrm{PH}$, indicating IDPA. This case indicated that IDPA should be ruled out in patients manifesting $\mathrm{PH}$.

Patients with PM can die of acute respiratory failure induced by infection. To prevent respiratory failure, rheumatologists should be careful about opportunistic infections in patients receiving high doses of corticosteroids or immunosuppressive drugs. Because respiratory failure can be fatal, patients with PM should stay away from crowds while they are taking high doses of immunosuppressive agents.

\section{Y MATSUKAWA N KITAMURA Y ASAI H ISHIZUKA Y KOYA $S$ NISHINARITA T HORIE}

First Department of Internal Medicine, Nihon University School of Medicine, Oyaguchi-Kamimachi, Itabashi 173-8610, Tokyo, Japan
K KANAI

Second Department of Internal Medicine, Nihon University School of Medicine

Correspondence to: Dr Matsukawa

m-2000@mbk.sphere.ne.jp

1 Abbot ME. Atlas of congenital cardiac disease New York: American Heart Association, 1936:65.

2 Greene DG, Baldwin EF, Baldwin JS, Himmelstein A, Roh CE, Cournand A. Pure congenital pulmonary stenosis and idiopathic dilatation of the pulmonary artery. Am J Med 1949;6:2440.

3 Deshmukh M, Guvenc S, Bentivoglio L, Goldberg $\mathrm{H}$. Idiopathic dilatation of the pulmonary artery. Circulation 1960;21:710-16.

4 Koya Y, Koura T, Mochimaru J, Iwata T, Kobayashi $\mathrm{T}$, Inoue $\mathrm{M}$, et al. A case of idiopathic dilatation of the pulmonary artery. Journal of Nihon University Medical Association 1993; 52:343-8. (In Japanese, abstract in English.)

5 Gould L, Reddy CVR, Gomprecht RF. Idiopathic dilatation of the pulmonary artery with pathic dilatation of the pulmonary artery with pulmonic

6 Andrews R, Colloby P, Hubner PJB. Pulmonary artery dissection in a patient with idiopathic of sudden cardiac death. Br Heart J 1993;69: of sudde.

7 Chang RY, Tsai CH, Chou YS, Wu TC. Idiopathic dilatation of the pulmonary artery. A case presentation. Angiology 1996;47:8792

8 Ugolini P, Mousseaux E, Sadou Y, Sidi D, Mercier LA, Paquet E, et al. Idiopathic dilatation of the pulmonary artery: report of four cases. Magn Reson Imaging 1999;17:933-7.

9 Watanabe K, Minami T, Nakajima Y. A 65-year-old woman presenting with a left hilar mass. J Cardiol 1999;34:285-7 (In Japanese.)

\section{Arthritis associated with non-alcoholic steatohepatitis}

Non-alcoholic steatohepatitis (NASH) is an entity characterised by mild abnormal liver function tests, a negative serological investigation, and histopathological findings similar to those seen in alcohol induced liver disease in patients who do not consume significant amounts of alcohol. Patients are usually asymptomatic but may complain of fatigue, malaise, or vague right upper quadrant pain. A low calorie diet is helpful in most of these patients. We present a case report of a patient with arthritis associated with NASH, which resolved completely after the introduction of a low calorie diet.

A 37 year old man presented with symmetrical arthritis during the past year affecting the elbows, wrists, shoulders, and knees. He had morning stiffness, which resolved after a one hour period of activity. On physical examination there was moderate tenderness of the elbows and wrists without swelling or limitation of the range of motion. Liver and spleen were not enlarged. Laboratory studies showed increased liver enzymes; aspartate aminotransferase 53 IU (normal <49 IU), alanine aminotransferase 98 IU (normal $<51$ IU), glutamyl transpeptidase 37 IU (normal $<34$ IU), alkaline phosphatase 64 IU (normal $<131 \mathrm{IU})$, and total bilirubin $16 \mu \mathrm{mol} / 1$. Serum cholesterol was $6.00 \mathrm{mmol} / 1$, triglycerides $1.62 \mathrm{mmol} / \mathrm{l}$, total protein $77 \mathrm{~g} / \mathrm{l}$, and albumin $50 \mathrm{~g} / 1$.

Sedimentation rate was $20 \mathrm{~mm} / 1 \mathrm{st} \mathrm{h}, \mathrm{C}$ reactive protein was normal, rheumatoid factor, antinuclear antibodies (ANA), hepatitis $B$ surface antigen, and antibodies to hepatitis $\mathrm{C}$ virus (HCV), smooth muscle, and mitochondria were all negative. He had IgG 
antibodies to Epstein-Barr virus, and cytomegalovirus. An $x$ ray examination of the hands and knees was negative. An ultrasound of the liver and spleen was normal.

His primary physician reported that the abnormal liver function tests had been present for approximately two years. A liver biopsy showed prominent macrovesicular fatty changes, aggregates of parenchymal inflammation, and mild fibrosis with minimal inflammatory infiltrate at some of the portal spaces. Fibrosis and Mallory bodies were not seen at the central vein areas. Iron staining was negative. These findings are consistent with a diagnosis of NASH.

The patient started on a low calorie diet and a few weeks later his liver function tests normalised with complete resolution of his joint symptoms. A few months later he stopped following the low calorie diet and within one week he began to have joint symptoms and the liver enzymes were found to be raised. Reintroduction of the low calorie diet again resulted in complete resolution of his symptoms and abnormal liver function tests.

Polyarthralgia or polyarthritis is one of the extrahepatic manifestations of liver diseases, and many chronic liver diseases are associated with rheumatic diseases. Examples include the association between chronic infection with hepatitis B virus and polyarteritis nodosa, ${ }^{1}$ the association between chronic infection with $\mathrm{HCV}$ and mixed cryoglobulinaemia, ${ }^{2}$ the association between chronic infection with HCV and Sjögren's syndrome, and the association of primary biliary cirrhosis and scleroderma.

Immune complexes may be one of the mechanisms of arthralgia associated with liver diseases, and patients with chronic liver disease due to $\mathrm{HCV}^{3}$ infection have been shown to have an increased prevalence of ANA, rheumatoid factor, and anti-smooth muscle antibodies.

Increasing evidence shows that several cytokines mediate hepatic inflammation and cholestasis in alcoholic and non-alcoholic steatohepatitis. Among these cytokines tumour necrosis factor $\alpha(\mathrm{TNF} \alpha)$ is a key factor. ${ }^{4} \mathrm{TNF} \alpha$ mediates not only the early stages of fatty liver but also the transition to more advanced stages of liver diseases like steatohepatitis and cirrhosis. On the other hand, $\mathrm{TNF} \alpha$ is an important inflammatory disease mediator in a wide spectrum of articular diseases, and inhibition of this cytokine led to a significant improvement of symptoms and signs in rheumatoid arthritis (RA). ${ }^{5}$ So TNF $\alpha$ may be a common mediator in NASH and arthritis.

Liver disease, however, may occur owing to connective tissue diseases which cause the joint symptoms, as has been found in patients with RA, ${ }^{6}$ Felty's syndrome, Still's disease, systemic lupus, giant cell arteritis, polyarteritis nodosa, and polymyalgia rheumatica. Histological liver changes are usually nonspecific. Our patient, however, had no evidence of RA or other rheumatic diseases.

There are numerous reports connecting the ingestion of certain food items and arthritis, ${ }^{7}$ with symptomatic improvement after the exclusion of certain types of food from the diet (elimination treatment). Dietary supplementation has resulted in mixed results in patients with $\mathrm{RA}$, with no response to the addition of vitamin $\mathrm{C}$, or zinc, but clinical benefits of diets enriched with fish oil ${ }^{8}$ or plant oils. Complete remission has been reported with a diet which included chicken type II collagen. ${ }^{9}$ However, low calorie diets have not been shown to reduce joint symptoms in patients with collagen vascular diseases.

We are unaware of previous publications showing an association between NASH and arthralgia or arthritis, and in fact joint symptoms were not reported in two large series of patient with NASH. ${ }^{10}{ }^{11}$ Still the unique response on two occasions of our patient's symptoms and abnormal liver function tests to a low calorie diet supports our hypothesis that the joint symptoms were associated with the NASH.
We thank Professor Paul Froom for his editorial assistance.

G S HABIB

W R SALIBA

Department of Internal Medecine B, Lady Davis Medical Centre, 7 Michal Street,

Haifa 34362, Israel

Correspondence to: Dr Habib

gshabib62@yahoo.com

1 Guillevin L, Lhote F, Leon A, Sauvaget F, Jarrousse B, Lortholary O, et al. Polyarteritis nodosa related to hepatitis $B$ virus: a prospective study with long-term observation of 41 patients. Medicine (Baltimore) 1995;74:238-53.

2 Agnello V, Romain PL. Mixed cryoglobulinemia secondary to hepatitis C virus infection

3 McMurray RW, Elbourne K. Hepatitis C virus infection and autoimmunity. Semin Arthritis Rheum 1997;26;689-701.

4 Tilg H, Diehl AM. Cytokines in alcoholic and nonalcoholic steatohepatitis. N Engl J Med 2000;343:1467-76.

5 Moreland LW, Baumgartner SW, Schiff MH, Tindall EA, Fleischmann RM, Weaver AL, et al. Treatment of rhematoid arthritis with a recombinant tumor necrosis factor receptor (p75)-Fc fusion protein. N Engl J Med (p75)-Fc fusion

6 Fernandes L, Sullivan S, McFarlane IG, Wojcicka BM, Warnes TW, Eddleston AL, et al. Studies on the frequency and pathogenesis of liver involvement in rheumatoid arthritis. Ann Rheum Dis 1979;38:501-6.

7 Parke AL, Hughes GVR. Rheumatoid arthritis and food: a case study. BMJ 1981;282:2027-9.

8 Kremer JM, Jubiz W, Michalek A, Rynes RI, Bartholomew LE, Bigaouette J, et al. Fish oil fatty acid supplementation in active rheumatoid fatty acid supplementation in active rheumatoid arthritis. A double-blinded, controlled, crosso-

9 Trentham DE, Dynesius-Trentham RA, Orav EJ, Combitchi D, Lorenzo C, Sewell KL, et al. Effects of oral administration of type II Effects of oral administration of type II collagen on rhe

10 Bacon B, Farahvash MJ, Janney CG, Neuschwander-Tetri BA. Nonalcoholic steatohepatitis: an expanded clinical entity. Gastroenterology 1994;107:1103-9.

11 Diehl AM, Goodman Z, Ishak KG. Alcohol-like liver disease in nonalcoholics. A clinical and histopoathological comparison with alcoholinduced liver injury. Gastroenterology 1988; $95: 1056-62$ 